\title{
PERFORMANCE OF FOUR DIFFERENT NANOPARTICLES IN BOUNDARY LAYER FLOW OVER A STRETCHING SHEET IN POROUS MEDIUM DRIVEN BY BUOYANCY FORCE
}

\author{
B. AMMANI KUTTAN and S. MANJUNATHA* \\ Department of Mathematics, Faculty of Engineering, CHRIST \\ Bengaluru- 560074, Karnataka, INDIA \\ E-mail: manjubhushana@gmail.com \\ S. JAYANTHI \\ Department of Mathematics, BMS College of Engineering \\ Bengaluru- 560019, Karnataka, INDIA \\ B.J. GIREESHA \\ Department of Studies and Research in Mathematics, Kuvempu University \\ Shankaraghatta-577 451, Shimoga, Karnataka, INDIA
}

\begin{abstract}
This contemporary work explores the theoretical analysis of energy transfer performance of distinct nanoparticles (silver, copper, aluminium oxide and titanium oxide) adjacent to a moving surface under the influence of a porous medium which is driven by the buoyancy force. A mathematical model is presented which is converted to similarity equations by employing similarity transformation. The condensed nonlinear equations were approximated by the iterative method called RKF 45th-order. The flow and energy transference characteristics are explained through graphs and tabulated values. The notable findings are: silver- water is an appropriate nanofluid for enhancing the thermal conductivity of the base fluid. Titanium oxide - water shows a lower fluid flow movement due to porosity.
\end{abstract}

Key words: natural convection, porous parameter, nanofluid, numerical solutions, volume fraction.

\section{Introduction}

The development of nanotechnology depends on a proper choice of nanoparticles asit possessessufficient or more chemical and physical properties to face the challenges in industries; it offers cushion to solve the problems they encounter on a day to day basis. Nanofluids are being used in the fields of nuclear waste management, food industries, paper industries, cooling systems, etc., asnanoparticles have a unique property of high thermal conductivity.Choi et al. [1], a pioneer in nanofluids, mentioned in their theoretical work that the thermal conductivity increased by two-fold when the nanoparticles were suspended into a normal fluid. Masuda et al. [2] and Minsta et al. [3] confirmed that the addition of a minor amount of nanoparticles to a regular fluid yielded a substantial improvement (10 to $50 \%$ ) in the thermal conductivity of ordinary fluids.

The metallurgy field, chemical industries, textile industry, paper industry, etc..., require the knowledge of flow and energy transference characteristics adjacent to moving surface. These engineering processes undergo cooling of strings by drawing them through a quiescent fluid. Sakiadis [4] instigated a theoreticalstudy on Blasius flow, later experimentally proven by Tsou et al. [5]. An extension work of [4] was carried out by Cran [6] and confirmed that the velocity of the moving surface was straightaway related to the distance from the slit. Chen [7] explored a similarity solution for two different cases like flow over the linear moving surface with linear surface temperature distribution and flow over the isothermal sheet.

\footnotetext{
To whom correspondence should be addressed
} 
Furthermore, many mathematicians have studied this theory of flow over a moving surface in the different physical situations [8-21].

Many industrial revolutions have been stimulated by the process of free convection in a porous medium. For instance, production of heat in the storage of farming crops, extraction of crude oil, design of pebble-bed nuclear reactors etc. Elbashbeshy and Aldawody [22] analyzed the importance of porosity in the fluid field over a moving surface. Gireesha et al. [23] explored the effect of suspended particles in porous media. Furthermore, many researchers analyzed different factors that influence fluid flow through porous media by considering normal fluids and nanoparticles [24-32]. Eid [33] conducted a study of a chemical reaction and heat generation or absorption effects due to an exponentially stretching sheet on an MHD mixed convective boundary layer flow of a nanofluid through a porous medium. Characteristics of heat transfer of gold nanoparticles (Au-NPs) in flow past a power-law stretching surface were discussed by Mohamed et al. [34], by considering a Sisko bio-nanofluid flow (with blood as a base fluid) in the presence of non-linear thermal radiation. Eid [35] analyzed the effects of slip velocity and heat generation/absorption on the timedependent stagnation-point flow and heat transfer of a nanofluid over a stretching sheet in a porous medium. Mohamed [36] reported that the mathematical model of the heat and mass transfer in a non-Newtonian fluid flow through a permeable nonlinear stretching vertical wall in the presence of effects such as, heat generation/absorption, thermal radiation, and heat and mass fluxesThe impact of the magnetic field and nanoparticles on the two-phase flow of a generalized non-Newtonian Carreau fluid over a permeable nonlinearly stretching surface was analyzed in the existence of suction/injection and thermal radiation by Mohamed et al. [37]. Al-Hossainy et al. [38] studied the impact of yield stress and convective conditions on a 3D mixed convection magneto-hydrodynamic boundary layer flow of a two-phase Casson nanofluid past a stretching plate in a porous medium.

The above reviews havenot addressedwhich nanoparticlesare suitable for excellent transfer of heat. The proper choice of nanoparticles will help to improve the effectiveness of fluid flow and thermal conductivity. Hence, a sincerer attempt is made to find the appropriate nanoparticle that increases the thermal conductivity of the base fluid. At this point, an examination of thermal characteristics of four different nanoparticles such as $\mathrm{Ag}, \mathrm{Cu}, \mathrm{Al}_{2} \mathrm{O}_{3}$ and $\mathrm{TiO}_{2}$ suspended in the base fluid water has been done. The fluid movement is considered in the porous media under the influence of buoyant force.

\section{Mathematical model}

A two- dimensional flow of a nanofluid adjacent to a moving surface through a permeable medium driven by buoyant force isconsidered. The viscosity of the base fluid is assumed to be varying with temperature.The $a_{1}$-axis is taken along the direction of the sheet and the $b_{1}$-axis is normal to it. The wall is assumed to be impermeable as shown in Fig.1. Under the aforesaid hypothesis, the mathematical model takes the following form

$$
\begin{aligned}
& \frac{\partial a_{1}}{\partial x_{1}}+\frac{\partial b_{1}}{\partial x_{2}}=0 \\
& \left(a_{1} \frac{\partial a_{1}}{\partial x_{1}}+b_{1} \frac{\partial b_{1}}{\partial x_{2}}\right) \rho_{n f}=\mu_{n f} \frac{\partial^{2} a_{1}}{\partial x_{2}^{2}}-\frac{\mu_{n f}}{K} a_{1}+g \rho_{n f} \beta_{n f}\left(T_{2}-T_{\infty}\right) \\
& a_{1} \frac{\partial T_{2}}{\partial x_{1}}+b_{1} \frac{\partial T_{2}}{\partial x_{2}}=\frac{K_{n f}}{(\rho C p)_{n f}} \frac{\partial^{2} T_{2}}{\partial x_{2}^{2}}
\end{aligned}
$$

Subjected to the boundary conditions

$$
\begin{array}{ll}
a_{1}=U_{w}=c x_{1}, \quad b_{1}=0, & T_{2}=T_{w} \quad \text { at } \quad x_{2}=0, \\
a_{1}=0, \quad T_{2}=T_{\infty} \quad \text { as } \quad & x_{2} \rightarrow \infty .
\end{array}
$$




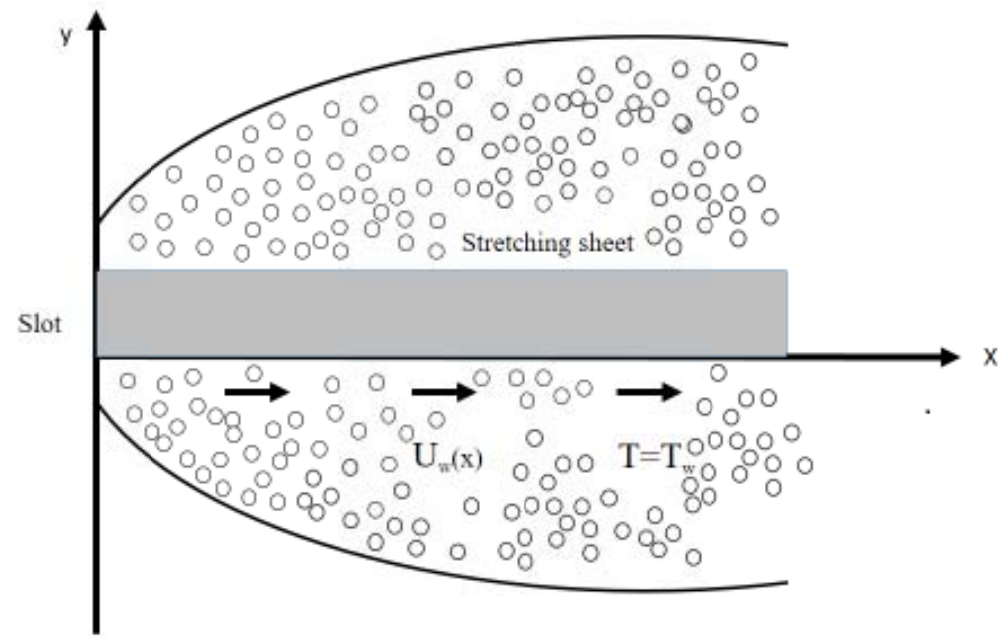

Fig.1. Physical geometry of the problem.

Table 1. Thermo- physical properties ofnanoparticles[39, 40].

\begin{tabular}{|l|c|c|c|c|c|}
\hline \multicolumn{1}{|c|}{ Property } & $\mathrm{TiO}_{2}$ & $\mathbf{A g}$ & $\mathbf{C u}$ & $\mathrm{Al}_{2} \mathrm{O}_{3}$ & $\mathrm{H}_{2} \mathrm{O}$ \\
\hline $\begin{array}{l}\text { Density }\left(\mathrm{kg} \cdot \mathrm{m}^{-3}\right) \\
\begin{array}{l}\text { Thermal conductivity } \\
\left(W . K^{-1} \cdot \mathrm{m}^{-1}\right)\end{array}\end{array}$ & 4250 & 5610 & 8933 & 3970 & 997.1 \\
\hline $\begin{array}{c}\text { Thermal expansion } \\
\text { coefficient }\left(K^{-1}\right)\end{array}$ & .0000157 & .00009 & .000076 & .000051 & .000256 \\
\hline Heat capacitance $\left(J K^{-1}\right)$ & 686.2 & 41.086 & 385 & 765 & 4179 \\
\hline
\end{tabular}

Table 2. Thermo physical model.

\begin{tabular}{|c|c|}
\hline Properties & Nanofluid \\
\hline Density $\left(\mathrm{kg} . \mathrm{m}^{-3}\right)$ & $\rho_{n f}=\left(1-\phi_{2}\right) \rho_{f}+\phi_{2} \rho_{s}$ \\
\hline Heat capacity $\left(J K^{-1}\right)$ & $(\rho C p)_{n f}=\left(1-\phi_{2}\right)(\rho C p)_{f}+\phi_{2}(\rho C p)_{s}$ \\
\hline Viscosity $\left(N s . m^{-2}\right)$ & $\mu_{n f}=\frac{\mu_{f}}{\left(1-\phi_{2}\right)^{2.5}}$ \\
\hline Thermal conductivity $\left(W . K^{-1} . m^{-1}\right)$ & $\frac{K_{n f}}{K_{f}}=\frac{K_{s}+(n-1) K_{f}-(n-1) \phi_{2}\left(K_{f}-K_{s}\right)}{K_{s}+(n-1) K_{f}+\phi_{2}\left(K_{f}-K_{s}\right)}$ \\
\hline Thermal expansion coefficient $\left(K^{-1}\right)$ & $\beta_{n f}=\left(1-\phi_{2}\right) \beta_{f}+\phi_{2} \beta_{s}$ \\
\hline
\end{tabular}


The fundamental thermo-physical properties of nanofluids at $25^{\circ} \mathrm{C}$ (remove this) were taken from various standard studiesand aregiven in Tabs 1 and 2.

The derived Eqs (2.1)-(2.3) are reduced into a pair of highly non-linear ordinary differential equations by employing the following similarity transformations

$$
a_{1}=c x_{1} f^{\prime}(\eta), \quad b_{1}=-\sqrt{c \mathrm{v}_{f}} f(\eta), \quad \eta=-\sqrt{c / \mathrm{v}_{f}} x_{2}, \quad \theta(\eta)=\frac{T_{2}-T_{\infty}}{T_{w}-T_{\infty}} .
$$

The resultant equations take the following form

$$
\begin{aligned}
& {\left[\left(1-\phi_{2}\right)+\phi_{2} \frac{\rho_{s 2}}{\rho_{f}}\right] *\left(1-\phi_{2}\right)^{2.5} *\left[-f^{\prime}(\eta)^{2}+f^{\prime \prime}(\eta) f(\eta)+\right.} \\
& \left.-\left[\left(1-\phi_{2}\right)+\phi_{2} \frac{\rho_{s 2}}{\rho_{f}}\right] * \lambda \theta(\eta)\right]+f^{\prime \prime \prime}(\eta)+D a^{*} f^{\prime}(\eta)=0, \\
& {\left[\left(1-\phi_{2}\right)+\phi_{2} \frac{(\rho C p)_{s 2}}{(\rho C p)_{f}}\right] * k_{f} \operatorname{Pr} f(\eta) \theta^{\prime}(\eta)+K_{n f} \theta^{\prime \prime}(\eta)=0 .}
\end{aligned}
$$

The boundary condition takes the following form by applying (2.5)

$$
f(0)=0, \quad f^{\prime}(0)=1, \theta(0)=1, f^{\prime}(\infty)=0, \theta(\infty)=0 .
$$

The local skin friction coefficient $C_{f}$ and local Nusselt number $\mathrm{Nu}_{x}$ are given by

$$
\begin{aligned}
& C_{f}=\frac{\mu_{n f}}{\rho_{f} u_{w}^{2}}\left(\frac{\partial a_{1}}{\partial x_{2}}\right)_{x_{2}=0}, \\
& \mathrm{Nu}_{x}=\frac{x_{1} K_{n f}}{k_{f}\left(T_{w}-T_{\infty}\right)}\left(-\frac{\partial T_{2}}{\partial x_{2}}\right)_{x_{2}=0} .
\end{aligned}
$$

Further, Eqs (2.9) and (2.10) get reduced to

$$
\begin{aligned}
& \operatorname{Re}_{x}{ }^{1 / 2} C_{f}=\frac{1}{\left(1-\phi_{2}\right)^{2.5}} f^{\prime \prime}(0), \\
& \operatorname{Re}_{x}^{-1 / 2} N u_{x}=-\frac{K_{n f}}{k_{f}} \theta^{\prime}(0) .
\end{aligned}
$$

\section{Numerical solution}

The Runge-Kutta-Fehlsberg $45^{\text {th }}$-order scheme is employed to solve the highly nonlinear differential Eqs (2.6) and (2.7) with the prescribed boundary condition (2.8). The acquired numerical results are 
compared with the previous results of Wang [41], Khan and Pop [42], and Gorla and Sidwai [43]. The results are in excellent agreement as shown in Tab.3.

Table 3. Comparison results for the temperature gradient $-\theta^{\prime}(0)$ for the parameter $\operatorname{Pr}$ when $\phi_{2}=\mathrm{Da}=\lambda=0$.

\begin{tabular}{|c|c|c|c|c|}
\hline Pr & Present Study & Wang[41] & Khan and Pop[42] & Gorla and Sidwai [43] \\
\hline 2.0 & 0.91135 & 0.9114 & 0.9113 & 0.9114 \\
\hline 6.13 & 1.75968 & - & - & - \\
\hline 7.0 & 1.89540 & 1.8954 & 1.8954 & 1.8954 \\
\hline 20.0 & 1.35390 & 1.3539 & 1.3539 & 1.3539 \\
\hline
\end{tabular}

\section{Results and discussion}

This section provides an insight intothe effect of the volume fraction of all the four nanoparticles on the free convection flow of nanofluids over a stretching sheet through a porous medium. Figures 2-12 are employed to interpret the results of the current research work regarding velocity $f^{\prime}(\eta)$, temperature $\theta(\eta)$ and the rate of temperature $-\theta^{\prime}(0)$. The following values are assumed for various parameters such as: volume fraction $0 \leq \phi_{2} \leq 0.3$, buoyancy $0 \leq \lambda \leq 3$, porosity $0 \leq \mathrm{Da} \leq 3$ for the computation of numerical values.

Figures 2-5 are drawn to explore the effect of $\phi_{2}$ on $f^{\prime}(\eta)$ in the case of $\mathrm{Cu}$-water, $\mathrm{Ag}$ water, $\mathrm{Al}_{2} \mathrm{O}_{3}$ water and $\mathrm{TiO}_{2}$ water. It is noted that $f^{\prime}(\eta)$ along the stretching sheet acclerated with a rise in $\phi_{2}$ in both the cases (i.e., $\mathrm{Cu}+\mathrm{H}_{2} \mathrm{O}$ and $\left.\mathrm{Ag}+\mathrm{H}_{2} \mathrm{O}\right)$. Furthermore, it is observed that $f^{\prime}(\eta)$ for $\mathrm{Cu}+\mathrm{H}_{2} \mathrm{O}$ is pridominantly higher than that of $\mathrm{Ag}+\mathrm{H}_{2} \mathrm{O}$. The velocity of the fluid with the suspension of $\mathrm{Al}_{2} \mathrm{O}_{3}$ and $\mathrm{TiO}_{2}$ particles increased with the increase in $\phi_{2}$ which is less compared to the $\mathrm{Cu}$-water and $\mathrm{Ag}$-water. The impact of the $\phi_{2}$ on the thermal distributionis shown in Figs 6 and 7. One can infer from these figures that escalation of $\phi_{2}$ from 0.1 and 0.3 lead to scattering of nanoparticles in the base fluid. As a result, the heat capacitance of the fluid increased; hence, the corresponding layer increased. Virtually, it is established that Ag nanofluid has more heat conducting capacitance than the other nanofluids which is due to the bulk thermal conductivity of $\mathrm{Ag}$ nanoparticles.

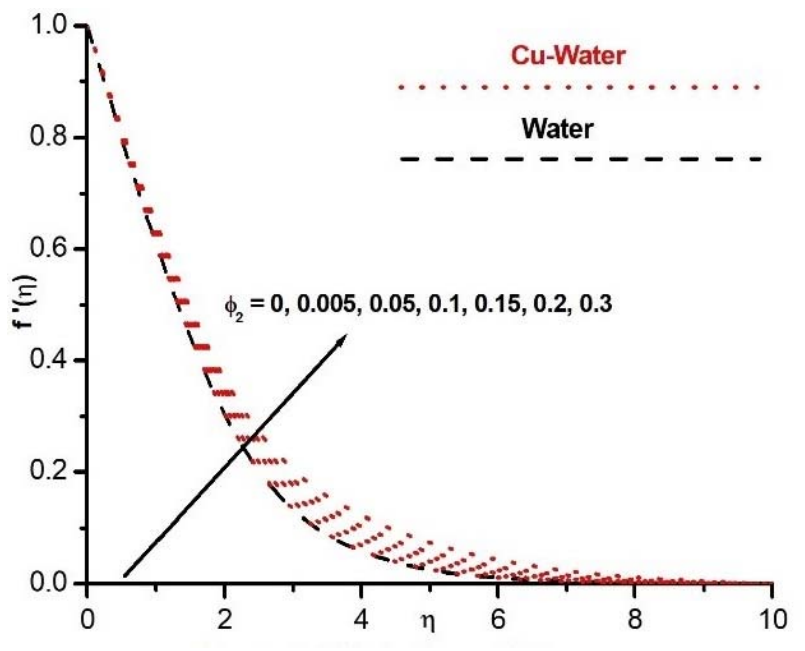

Fig.2. Effect of $\phi_{2}$ on $f^{\prime}(\eta)$.

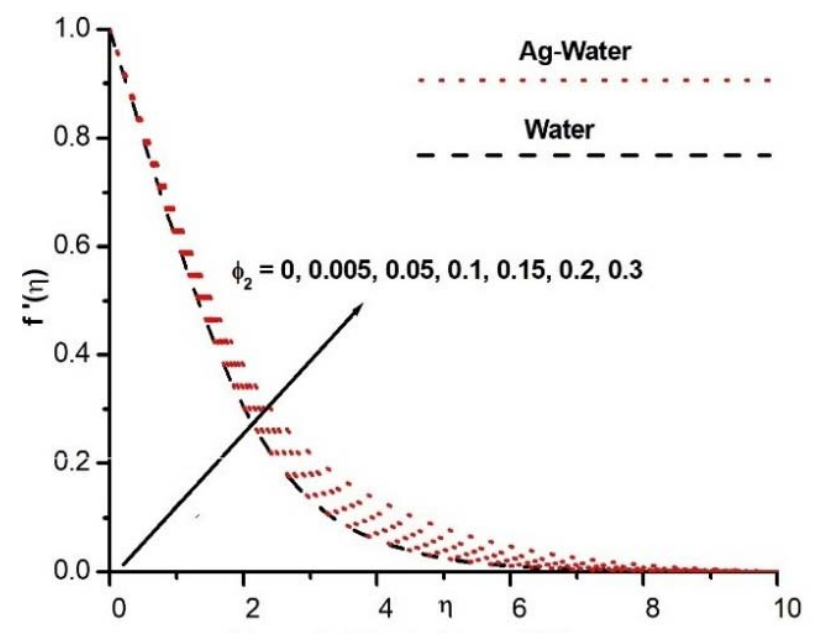

Fig.3. Effect of $\phi_{2}$ on $f^{\prime}(\eta)$. 

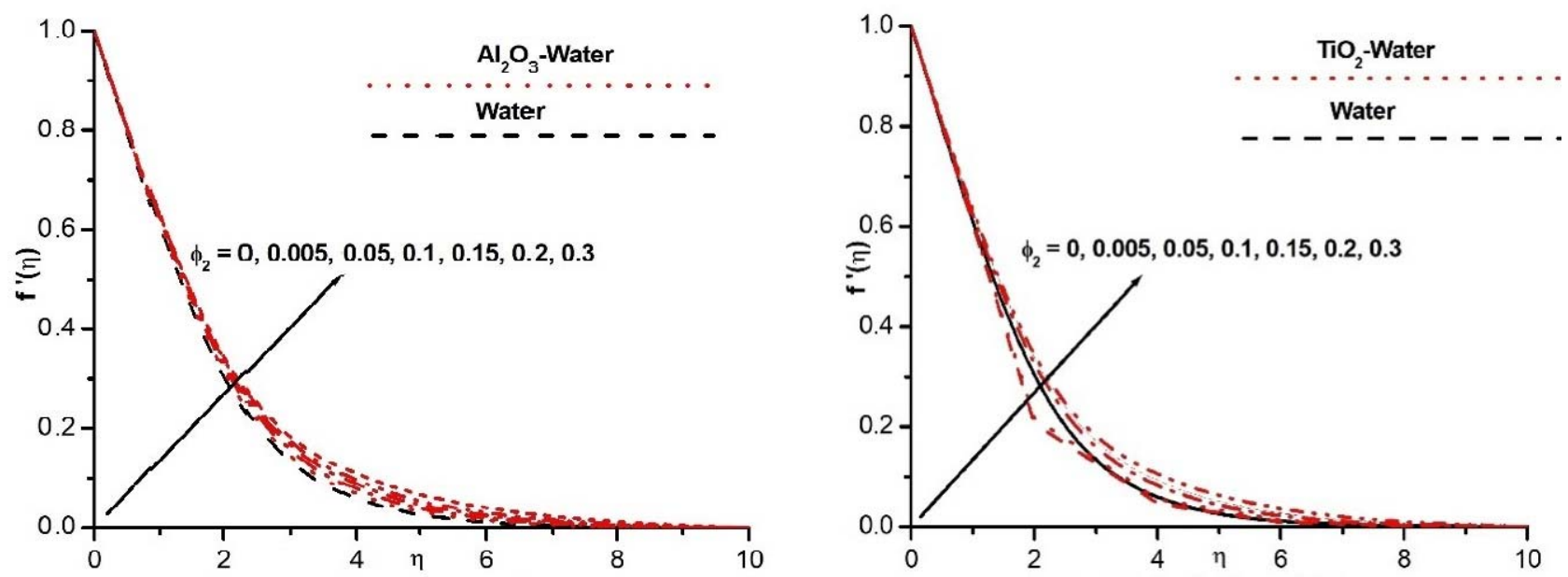

Fig.4. Effect of $\phi_{2}$ on $f^{\prime}(\eta)$.

Fig.5. Effect of $\phi_{2}$ on $f^{\prime}(\eta)$.

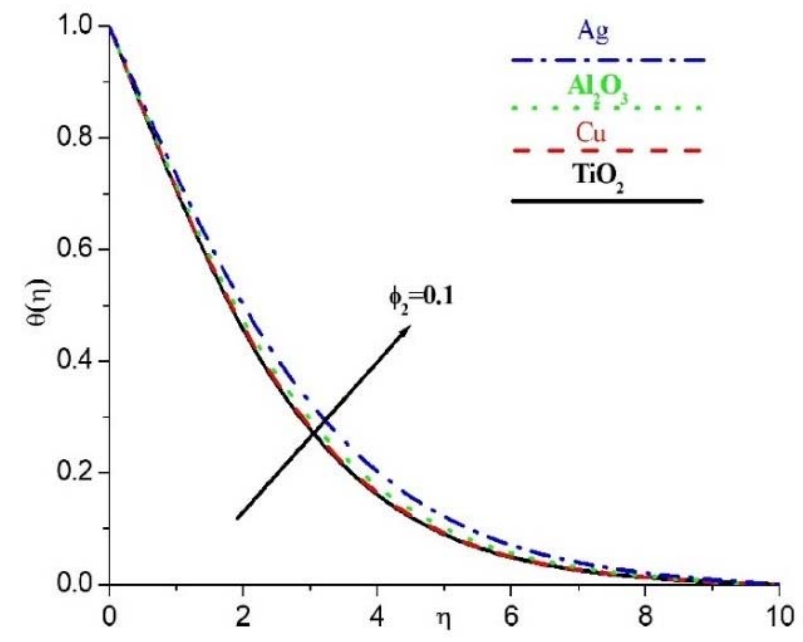

Fig.6. Effect of $\phi_{2}$ on $\theta(\eta)$ for various nanoparticles.

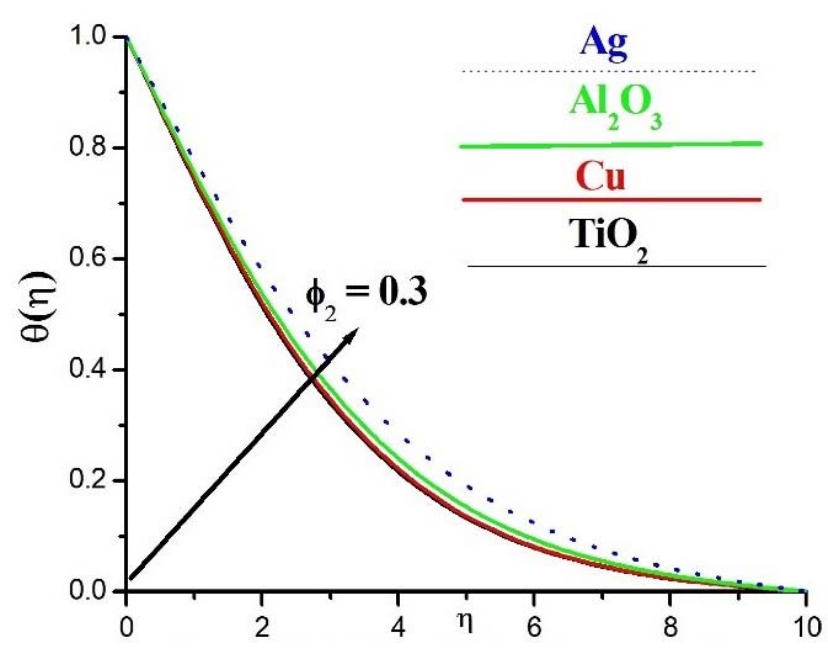

Fig.7. Effect of $\phi_{2}$ on $\theta(\eta)$ for various nanoparticles.

Figure 8 illustrates the nature of $f^{\prime}(\eta)$ for various nanofluids when $\mathrm{Da}=2 . \mathrm{TiO}_{2}$-water nanofluid showsa lower velocity profile than other nanofluids.Figure 9 discloses the impact of Da on $\theta(\eta)$ for different nanofluids. Ag -water showsa greater thermal conductivity compared to other nanofluids when $\mathrm{Da}=2$. The buoyancy effect $(\lambda)$ on velocity $f^{\prime}(\eta)$ and temperature $\theta(\eta)$ is depicted in Figs 10 and 11. From Fig.10, it is inferred that $\mathrm{Ag}$ nanoparticles has more fluid flow than other nanoparticles. Physically, this indicates the expansion of convection currents in Ag nanoparticles is higher than for other nanoparticles. Figure 11 shows that $\theta(\eta)$ is more for Ag nanofluids.

Figure 12 portrays the nature of the rate of heat transfer $-\theta^{\prime}(0)$ over different values of volume fraction $\phi_{2}$ for the four different nanofluids. Silver (Ag) nanoparticles have abetter rate of heat transfer and titanium oxide hasthe least when compared to other nanoparticles. 


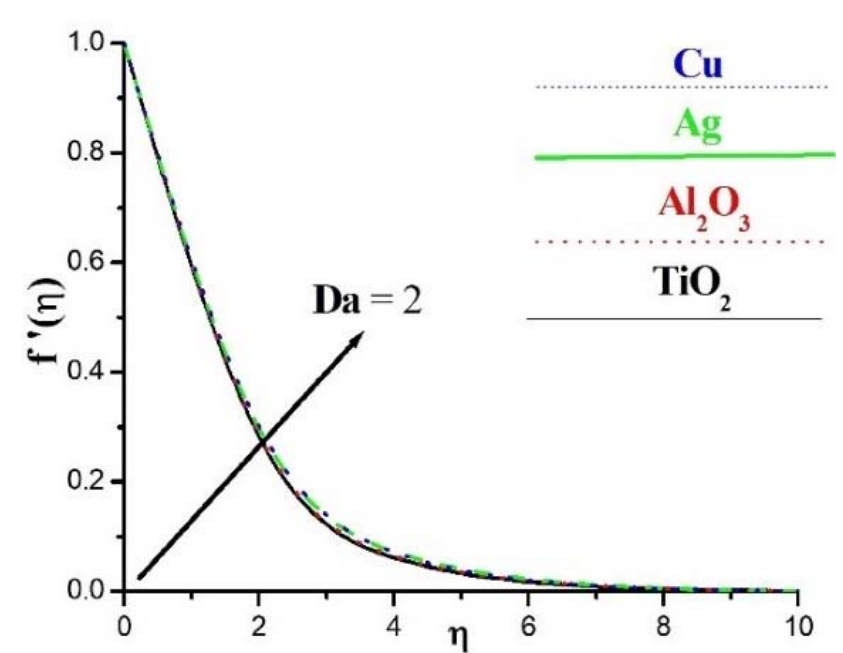

Fig.8. Effect of Da on $f^{\prime}(\eta)$ for various nanoparticles.

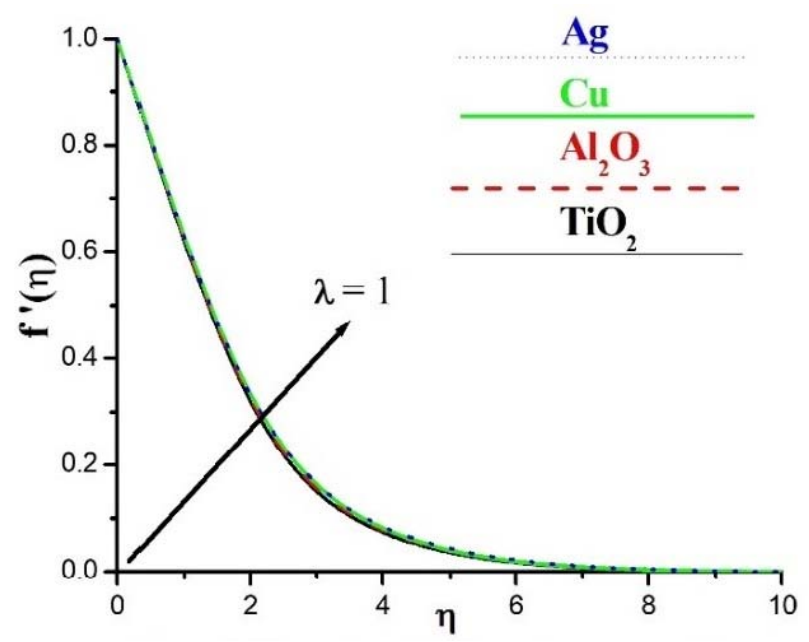

Fig.10. Effect of $\lambda$ on $f^{\prime}(\eta)$ for various nanoparticles. nanoparticles.

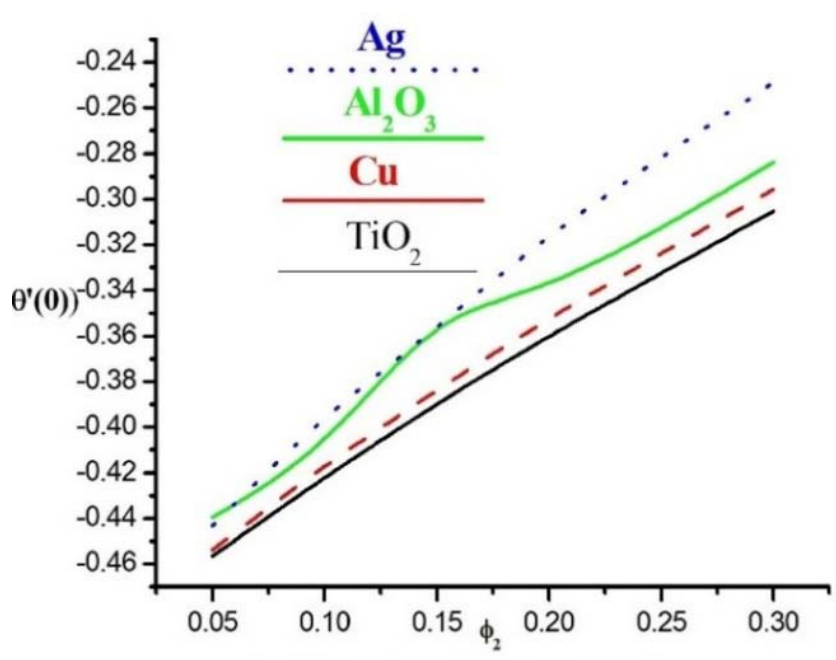

Fig.12. Effect of $\phi_{2}$ on $\theta^{\prime}(0)$.

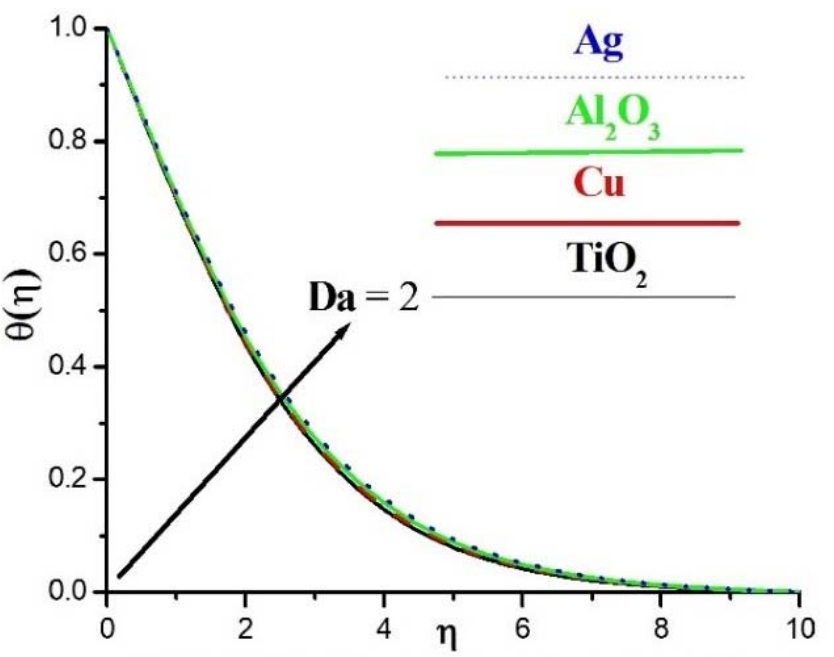

Fig.9. Effect of Da on $\theta(\eta)$ for various nanoparticles.

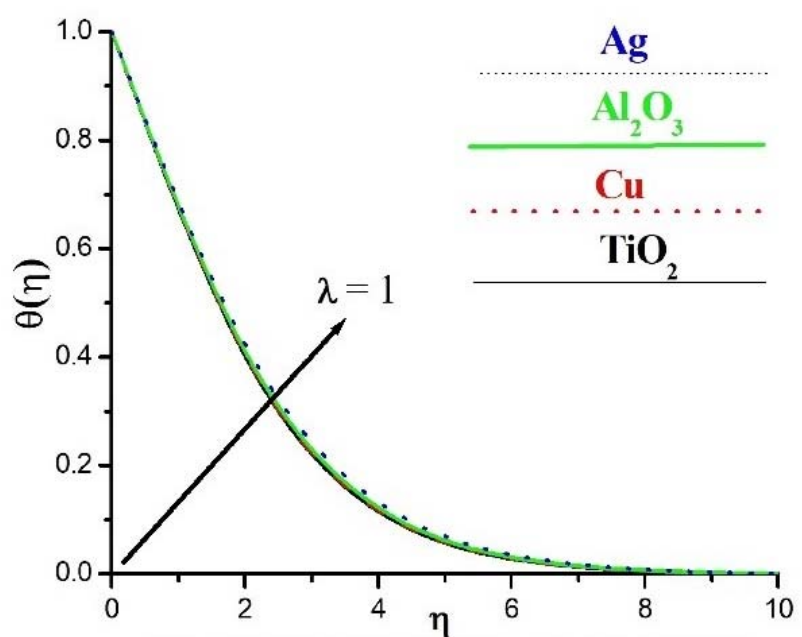

Fig.11. Effect of $\lambda$ on $\theta(\eta)$ for various 


\section{Conclusion}

The impact of various nanoparticles on the boundary layer flow through a porous medium over a stretching sheet in the presence of buoyant force is theoretically studied by using graphs. An increase in the volume fraction increased the thermal conductivity as well as the rate of heat transfer of $\mathrm{Ag}-\mathrm{H}_{2} \mathrm{O}$ nanofluids and a reverse effect is observed for $\mathrm{TiO}_{2}-\mathrm{H}_{2} \mathrm{O}$. Hence, it is concluded that $\mathrm{Ag}-\mathrm{H}_{2} \mathrm{O}$ is the appropriate nanofluid for enhancing the thermal conductivity of the base fluid (water). It is also observed that $\mathrm{TiO}_{2}-\mathrm{H}_{2} \mathrm{O}$. has a lower fluid movement due to porosity of the medium.

\section{Nomenclature}

$$
\begin{aligned}
& a_{I}\left(m \cdot s^{-1}\right) \text { - velocity component along } x_{1} \text { the axis } \\
& b_{1}\left(m . s^{-1}\right) \text { - velocity component along } x_{2} \text { the axis } \\
& c_{S}\left(J . K^{-1}\right) \text { - heat capacity of solid surface } \\
& D a=\frac{v_{f}}{K c} \quad-\text { porous medium parameter } \\
& g\left(m . s^{-2}\right) \text { - acceleration due to gravity } \\
& K_{n f}\left(w \cdot K^{-1} \cdot m^{-1}\right) \text { - effective thermal conductivity of nanofluid } \\
& k_{f}\left(w \cdot K^{-1} \cdot m^{-1}\right) \quad \text { - thermal conductivity of the fluid } \\
& k_{s}\left(w \cdot K^{-1} \cdot m^{-1}\right) \text { - thermal conductivity of the solid } \\
& T_{2}(K) \text { - temperature of the nanofluid } \\
& T_{\infty}(K) \quad \text { - temperature of the ambient fluid } \\
& U_{w}\left(m . s^{-1}\right)-\text { stretching velocity of sheet } \\
& \alpha_{n f}\left(m^{2} \cdot s^{-1}\right) \text { - thermal diffusivity of nanofluid } \\
& \beta_{n f}\left(K^{-1}\right)-\text { coefficient of thermal expansion of nanofluid } \\
& \lambda=\frac{g \beta_{f}\left(T_{w}-T_{\infty}\right)}{c^{2} x}-\text { convection parameter } \\
& \mu_{f}\left(N s . m^{-2}\right) \text { - viscosity of the fluid } \\
& \mu_{n f}\left(N s . m^{-2}\right) \text { - effective viscosity of nanofluid } \\
& \phi_{2}-\text { solid volume fraction of nanoparticle } \\
& \rho_{f}\left(\mathrm{~kg} . \mathrm{m}^{-3}\right) \text { - reference density of fluid fraction } \\
& \rho_{n f}\left(k g . m^{-3}\right) \text { - effective density of the nanofluid } \\
& \rho_{s}\left(\mathrm{~kg} \cdot \mathrm{m}^{-3}\right) \text { - reference density of water }
\end{aligned}
$$

\section{References}

[1] Choi S.U.S (1995): Enhancing thermal conductivity of fluids with nanoparticles. - The Proceedings of the 1995 ASME International Mechanical Engineering Congress and Exposition, San Francisco, USA, ASME, FED 231/MD 66, pp.99-105.

[2] Masuda H., Ebata A., Teramea K. and Hishinuma N. (1993):Altering the thermal conductivity and viscosity of liquid by dispersing ultra-fine particles.- Netsu Bussei., vol.7, No.4, pp.227-233. 
[3] Minsta H.A., Roy G., Nguyen C.T. and Doucet D. (2009): New temperature dependent thermal conductivity data for water-based nanofluids. - International Journal of Thermal Sciences. vol.48, pp.363-371.

[4] Sakiadis B.C. (1961): Boundary layer behaviour on continuous solid surface; the boundary layer equations for twodimensional and axisymmetric flow of a dusty fluid. - A.I. Ch. E.J, vol.7, No.1, pp.26-28.

[5] Tsou F.K., Sparrow E.M. and Glodstein R.J. (1967): Flow and heat transfer in the boundary layer on a continuous moving surface.- Int. J. Heat Mass Transfer, vol.10, pp.219-235.

[6] Crane L.J. (1970): Flow past a stretching plate.- Zeitschrift fur Angewandte Mathematik and Physik ZAMP, vol.21, pp.645-647.

[7] Chen C.H. (1998): Laminar mixed convection adjacent to vertical, continuously stretching sheets.- Heat and Mass Transfer, vol.33, pp.471-476.

[8] Khan W.A. and Pop I. (2010): Boundary-layer flow of a nanofluid past a stretching sheet.- International Journal of Heat and Mass Transfer, vol.53, pp.2477-2483.

[9] Magyari E. and Keller B. (1999): Heat and mass transfer in the boundary layers on an exponentially stretching continuous surface.- J. Phys. D: Appl. Phy., vol.32, pp.577-585.

[10] Elbashbeshy E.M.A. (2001): Heat transfer over an exponentially stretching continuous surface with suction. Archives of Mechanics, vol.53, pp.643-651.

[11] Al-Odat R.A.M.Q., Damesh T.A. and Al-Azab T.A. (2010): Thermal boundary layer on an exponentially stretching continuous surface in the presence of magnetic field effect.- International Journal of Applied Mechanics and Engineering, vol.11, pp.289-299.

[12] Partha M.K., Murthy P.V.S.N. and Rajasekhar G.P. (2005):Effect of viscous dissipation on the mixed convection heat transfer from an exponentially stretching surface.- Heat and Mass Transfer, vol.41, pp.360-366.

[13] Sanjayanand E. and Khan S.K. (2006):On heat and mass transfer in a viscoelastic boundary layer flow over an exponentially stretching sheet. - International Journal of Thermal Sciences, vol.45, pp.819-828.

[14] Khan S.K. (2006): Boundary layer viscoelastic fluid flow over an exponentially stretching sheet. - International Journal of Applied Mechanics and Engineering, vol.11, pp.321-335.

[15] Mustafa M., Hayat T., Pop I., Asghar S. and Obaidat S. (2011): Stagnation-point flow of a nanofluid towards a stretching sheet. - International Journal of Heat and Mass Transfer, vol.54, pp.5588-5594.

[16] Sharidan S., Mahmood T. and Pop I. (2006): Similarity solutions for the unsteady boundary layer flow and heat transfer due to a stretching sheet.- Int. J. Appl. Mech. Eng., vol.11, No.3 pp.647-654.

[17] Gireesha B.J., Manjunatha S. and Bagewadi C.S. (2012): Unsteady hydromagnetic boundary layer flow and heat transfer of dusty fluid over a stretching sheet. - Afr. Metametika, vol.23, No.2, pp.229-241.

[18] Manjunatha S. and Gireesha B.J. (2016): Effects of variable viscosity and thermal conductivity on MHD flow and heat transfer of a dusty fluid. -Ain Shams Engineering Journal, vol.7, pp.505-515.

[19] Grubka L.J. and Bobba K.M. (1985): Heat transfer characteristics of a continuous stretching surface with variable temperature. - Int. J. Heat Mass Transfer, vol.107, pp.248-250.

[20] Mahapatra T.R. and Gupta A.S. (2003): Heat transfer in stagnation point flow towards a stretching surface. -Heat Mass Transfer, vol.32, pp.517-521.

[21] Andersson H.I., Aareseth J.B. and Dandapat B.S. (2000): Heat transfer in a liquid film on an unsteady stretching surface. - Int. J. Heat Mass Transfer, vol.43, pp.69-74.

[22] Elbashbeshy E.M.A. and Aldawody D.A. (2010): Effect of thermal radiation and magnetic field on unsteady mixed convection flow and heat transfer over a porous stretching surface. - Int. J. Nonlinear Sci., vol.9, No.4, pp.448-454.

[23] Gireesha B.J., Mahanthesh B., Gorla R.S.R. and Manjunatha P.T.(2016): Thermal radiation and hall effects on boundary layer flow past a non isothermal stretching surface embedded in porous medium with non uniform heat source/sink and fluid particle suspension.- Heat Mass Transfer, vol.52, No.4, pp.897-911.

[24] Krishnamurthya M.R., Prasanna Kumara B.C., Gireeshaa B.J. and Gorla R.S.R. (2016): Effect of chemical reaction on MHD boundary layer flow and melting heat transfer of Williamson nanofluid in porous medium.- Engineering Science and Technology, an Int. Journal, vol.19, No.1, pp.53-61. 
[25] Manjunatha S., Gireesha B.J., Eshwarappa K.M. and BagewadiC.S.(2013): Similarity solutions for boundary layer flow of a dusty fluid through a porous medium over a stretching surface with internal heat generation/absorption.- J. of Porous Media, vol.16, pp.501-514.

[26] Cheng C-Y. (2006): Natural convection heat and mass transfer of non-Newtonian power law fluids with yield stress in porous media from a vertical plate with variable wall heat and mass fluxes. - Int. Comm. Heat Mass Transfer, vol.33, pp.1156-1164.

[27] Chamkha A.J., Al-Mudhaf A.F. and Pop I. (2006): Effect of heat generation or absorption on thermophoretic free convection boundary layer from a vertical flat plate embedded in a porous medium.- Int. Comm. Heat Mass Transfer, vol.33, pp.1096-1102.

[28] Magyari E., Pop I. and Postelnicu A. (2007): Effect of the source term on steady free convection boundary layer flows over a vertical plate in a porous medium. - Part I. Transp. Porous Media, vol.67, pp.49-67.

[29] Nield D.A. and Kuznetsov A.V. (2008): Natural convection about a vertical plate embedded in a bi-disperse porous medium.- Int. J. Heat Mass Transfer, vol.51, pp.1658-1664.

[30] MahdyA. and Hady F.M. (2009): Effect of thermophoretic particle deposition in non- Newtonian free convection flow over a vertical plate with magnetic field effect.- J. Non- Newtonian Fluid Mech,. vol.161, pp.37-41.

[31] Ibrahim F.S., Hady F.M., Abdel-Gaied S.M. and Eid M.R. (2010): Influence of chemical reaction on heat and mass transfer of non-Newtonian fluid with yield stress by free convection from vertical surface in porous medium considering Soret effect.- Appl. Math. Mech. - Engl. Ed. vol.31, No.6, pp.675-684.

[32] Prasannakumara B.C., Shashikumar N.S. and Venkatesh P. (2017): Boundary layer flow and heat transfer of fluid particle suspension with nanoparticles over a nonlinear stretching sheet embedded in a porous medium. Nonlinear Engineering, vol.6, No.3, pp.179-190.

[33] Eid M.R. (2016): Chemical reaction effect on MHD boundary-layer flow of two-phase nanofluid model over an exponentially stretching sheet with a heat generation.- Journal of Molecular Liquids, vol.220, pp.718-725.

[34] Eid M.R., Alsaedi A., Muhammad T. and Hayat T. (2017): Comprehensive analysis of heat transfer of gold-blood nanofluid (Sisko-model) with thermal radiation. - Results in Physics, vol.7, pp.4388-4393.

[35] Eid Mohamed R. (2017): Time-dependent flow of water-NPS over a stretching sheet in a saturated porous medium in the stagnation-point region in the presence of chemical reaction.- Journal of Nanofluids, vol.6, No.3, pp.550-557.

[36] Eid Mohamed R. and Mishra S.R. (2017): Exothermically reacting of non-Newtonian fluid flow over a permeable nonlinear stretching vertical surface with heat and mass fluxes. - Computational Thermal Sciences, vol.9, No.4, pp.283-296.

[37] Eid Mohamed R., Kasseb L. Mahny, Taseer Muhammad and Mohsen Sheikholeslam (2018): Numerical treatment for Carreau nanofluid flow over a porous nonlinear stretching surface. - Results in Physics, vol.8, pp.1185-1193.

[38] Al-Hossainy A.F., Eid M.R. and Zoromba M.S. (2019): SQLM for external yield stress effect on 3D MHD nanofluid flow in a porous medium.- Physica Scripta.

[39] Tanzila Hayat and Nadeem S. (2017): Heat transfer enhancement with Ag-CuO/water hybrid nanofluid. - Results in Physics, vol.7, pp.2317-2324.

[40] Abolfazl Zaraki, Mohammad Ghalambaz, Ali J. Chamkha, Mehdi Ghalambaz and Danilo De Rossi (2015): Theoretical analysis of natural convection boundary layer heat and mass transfer of nanofluids: Effects of size, shape and type of nanoparticles, type of base fluid and working temperature. - Advanced Powder Technology,vol.26, pp.935-946.

[41] Wang C.Y. (1989): Free convection on a vertical stretching surface. - J. Appl. Math. Mech. (ZAMM), vol.69, pp.418-420.

[42] Khan W.A. and Pop I. (2010): Boundary-layer flow of a nanofluid past a stretching sheet. - International Journal of Heat and Mass Transfer, vol.53, pp.2477-2483.

[43] Gorla R.S.R. and Sidawi I. (1994): Free convection on a vertical stretching surface with suction and blowing. Appl. Sci. Res. vol.52, pp.247-257. 